\title{
"The Effect of Recreational Program by Using Small Games on Learning some of the Rhythmic Gymnastics Skills and Improving Self-Confidence for Sixth Grade Students"
}

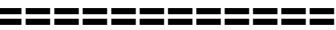

\author{
Prof. Dr. Mohamed Abdl Aziz Salama ${ }^{1}$ \\ Dr. Safwat Ali Gomaa ${ }^{2}$ \\ Dr.Rasha Mohamed Abdel Salam ${ }^{3}$
}

\section{Introduction and research problem}

Our Eastern societies in general and the Egyptian society in particular suffer from some constraints facing girls. One of these constrains is practicing sports activities. This is because of the lack of conviction of exercising sports activities or because of parents' opinions or customs and traditions, which puts restrictions on exercising sports. These restrictions are sport type or private sports uniforms or falling on the ground during practices. Also, primary education is considered as a critical transition stage in girls' life, where in this age some physiological changes occur to girls, like the appearance of the breasts and the new shape of buttocks and the manifestations of puberty. All these factors reduce self-confidence. So, the researchers thought how to attract girls to practice sports activities, especially rhythmic gymnastics, where this sport is listed in the curriculum of this stage and how to invest these activities in improving self-confidence through proposed recreational program using small games.

Recreation is one of the areas that help in building the child's personality. It gives him opportunities to express himself, his abilities and his creations. The field of recreation is rich with activities that satisfy the need of the child to move, meditate, think and be creative. (9:12)

Mohammed Abdullah (2005) shows that small games play an important role in changing lessons from its rigid routine based on traditional exercises to creative style filled with pleasure among students. (8: 148)

Jaster jembskaia \& Titov (1999) refer that rhythmic gymnastics is a sport characterized by a mixture of sports, art, dance and ballet. Rhythmic gymnastics is characterized by the multiplicity and diversity of motor skills. The body skills (jumps-

\footnotetext{
1 Professor of Sports Management , Recreation and Sports Management Department- Faculty of Physical Education for Boys, ${ }^{\text {Alexandria University. }}$

2 . Lecturer, Sports Administration and Recreation Department, Faculty of Physical Education for Boys, Alexandria University.
}

3. Lecturer, Curriculum and Teaching Methods of Physical Education Department, Faculty of Physical Education for Girls, Alexandria University. 
leaps -Balances -Pivot -Waves-Flexibility) are considered as a basic rule of building the movement sequences (Individual - group). (6:13)

The importance of self-confidence for children appears in dealing with stress, and making decisions. Poor self-confidence may lead to some emotional and mental problems such as depression that results from a lack of self-confidence, and if the one couldn't overcome these bad hopelessness feelings, he may commit suicide.

Abdel Fattah al-Khawaja (2001) identifies self-confidence that the one recognizes his skills, and his abilities to deal effectively with different situations. (2: 135)

\section{Purpose of the study:}

1- Designing a recreational program by using small games to learn some rhythmic -gymnastics skills and develop self-confidence for sixth grade (female) students.

2- Identifying the impact of the proposed program on:

a- Cognitive Achievement rhythmic gymnastics skills.

b- Technical performance of rhythmic gymnastics skills (Front wave - Arch Jump - Open Turn - Balance Passe ).

c- Self-confidence of sixth grade (female) students.

\section{Hypotheses of the study :}

a- There are significant differences between pretests and posttests in cognitive achievement in favor of the posttests.

b- There are significant differences between pretests and posttests in the technical performance of rhythmic gymnastics (Front wave - Arch Jump - Open Turn Balance Passe ) and in favor of the posttests.

c- There are significant differences between pretests and posttests in self-confidence of sixth grade (female) students and in favor of the posttests.

\section{Research Procedures:}

\section{Methodology :}

Researchers used the experimental approach with one experimental with pretests and posttests.

\section{Research sample:}

20 female students from sixth grade were chosen and homogenization process was conducted for the research's sample in the variables of (age - height - weight) and in 
cognitive achievement, technical performance and self-confidence after taking the written consent of students and parents to participate in the program

\section{Measurements and data collecting tools:}

1. Restameter: to measure the total length of the body to the nearest $\mathrm{cm}$.

2. Calibrated medical balance: to measure the weight to the nearest $\mathrm{kg}$.

\section{Test of cognitive achievement:}

The use of cognitive achievement test to identify the extent of the collection of information for students and knowledge skills in question, to design a cognitive achievement test; researchers followed the coming steps: defining the goal of the test, determining the educational goals, analyzing the rhythmic gymnastics skills (Front wave - Arch Jump - Open Turn - Balance Passe ) through reviewing the references and previous studies, formulating the test's questions, ordering the test's questions, formulating the instructions, displaying this test on a group of judges, experimenting the test.

\section{Note Card of Rhythmic Gymnastics skills under Study:}

To design a Note Card of Rhythmic Gymnastics skills; researchers followed the coming steps: reviewing references and studies in the field of rhythmic gymnastics to identify the note card's content, identifying the note card's axes through these skills (Front wave - Arch Jump - Open Turn - Balance Passe ), so the card consists of motor performance stages (preliminary stage - basic stage - final stage), analyzing the motor performance stages to technical points, which include various performance aspects of the skills, giving a point for each technical aspect, the degree of each stage is the total points of each technical aspect.

\section{Self-Confidence Scale : -}

Researchers used the self-Confidence Scale prepared by Aida Shaban and Awad Sumeiri (2009) (4) and some statements were modified to suit the nature of the current study. The scale consists of (34) statement distributed over the following axes: selfacceptance, others-acceptance, social activity, emotional balance, the ability to face problems. Researchers specified four choices with specified points for each choice according to Likert scale as the following: (1 = disagree, $2=\mathrm{I}$ agree to some extent, $3=$ agree, $4=$ strongly agree). The total degree of the scale ranges between $(34-136$ 
degrees), where (136) represents maximum self-confidence of the student, and (34) shows low self-confidence.

\section{Small games of the proposed recreational program:}

For designing this proposed program the researchers reviewed references, Was selected skills in question (Front wave - Arch Jump - Open Turn - Balance Passe) as they exist in the physical education curriculum for this stage and based on the opinion of experts was then, and previous studies that are similar this research, determined the objectives of the program, identified the sample, set up the program in its initial shape and presented it to the experts in the fields of rhythmic gymnastics and recreation. The number of the experts is (5) and the results led to delete or add some exercise and formulations. The proposed program has been divided into (24) units by two units a week and for a period of 12 weeks. The unit lasted for 45 minutes.

\section{Scientific Factors of Data:}

\section{First: Validity:}

- Content validity: The researchers depended on the sincerity of the experts in order to identify to what extent the phrases and elements are suitable for the program where some elements have been deleted and modified and added, based on the opinions of experts.

\section{Second: Reliability:}

- Re-test method: the researchers calculated reliability through test and re-test after a period of (15 days) for a sample selected randomly from the original community and outside the study's sample.

\section{Basic study:}

Pretest and posttest of the research, as well as the program were conducted in the period from 21/02/2015 until 05/28/2012.

\section{Statistical Treatments:}

Researchers used Spss program in the extraction of the following statistical treatments: the Mean - standard deviation - Skewness coefficient - Percentage percentage of improvement - (T) Test (v) - Eta squared- effect size equations, according to the equations of Cohen.

\section{Results:}


Table (1)

Statistical Signs of Cognitive Achievement, Technical Performance and Improvement Percentage According to Pretest and Posttest $\quad \mathbf{n = 2 0}$

\begin{tabular}{|c|c|c|c|c|c|c|c|c|c|}
\hline \multirow{2}{*}{$\begin{array}{l}\text { Statistical } \\
\text { Signs }\end{array}$} & \multicolumn{2}{|c|}{ Pretest } & \multicolumn{2}{|c|}{ Posttest } & \multicolumn{2}{|c|}{$\begin{array}{c}\text { Difference between } \\
\text { two Means }\end{array}$} & \multirow[b]{2}{*}{ T Value } & \multirow[b]{2}{*}{ Significance } & \multirow{2}{*}{$\begin{array}{l}\text { Improvemen } \\
\text { Percentage \% }\end{array}$} \\
\hline & Mean & $\begin{array}{c}\text { Std. } \\
\text { Deviation } \\
\pm \\
\end{array}$ & Mean & $\begin{array}{c}\text { Std. } \\
\text { Deviation } \\
\pm\end{array}$ & Mean & $\begin{array}{c}\text { Std. } \\
\text { Deviation } \\
\pm\end{array}$ & & & \\
\hline $\begin{array}{c}\text { Cognitive } \\
\text { Achievement }\end{array}$ & 7.45 & 1.00 & 22.05 & 3.38 & 14.60 & 3.87 & $16.86 *$ & 0.00 & 195.97 \\
\hline Front wave & 2.80 & 1.15 & 7.15 & 0.75 & 4.35 & 0.81 & 23.94* & 0.00 & 155.36 \\
\hline Arch Jump & 3.20 & 1.15 & 6.95 & 0.60 & 3.75 & 1.33 & $12.58 *$ & 0.00 & 117.19 \\
\hline Open Turn & 2.30 & 1.22 & 7.45 & 0.94 & 5.15 & 1.66 & $13.85^{*}$ & 0.00 & 223.91 \\
\hline Balance Passe & 3.75 & 0.55 & 9.05 & 0.76 & 5.30 & 0.80 & 29.58* & 0.00 & 141.33 \\
\hline
\end{tabular}

Correlation is significant at the 0.05 level $=2.09$

It is clear from the above table that there are statistically significant differences in the level of (0.05), where the value of (T) ranged between (12.58 to 29.58), which is greater than the tabulated value of $(\mathrm{T})$ at the level $(0.05)$ with level of significance less than 0.05 , and the improvement ratios ranged between $(117.19 \%$ to $223.91 \%)$ for the benefit of posttest in all the variables under consideration.

Table (2)

Significance of the Effect Size of Cognitive Achievement and the Technical Performance according to Cohen Equations $n=20$

\begin{tabular}{|c|c|c|c|c|c|c|}
\hline Statistical Signs & $\begin{array}{c}\text { Measurement } \\
\text { Unit }\end{array}$ & T Value & Significance & $\begin{array}{c}\text { Eta } \\
\text { Squared }\end{array}$ & $\begin{array}{c}\text { Effect } \\
\text { Size }\end{array}$ & $\begin{array}{c}\text { Significance of } \\
\text { Effect Size }\end{array}$ \\
\hline Cognitive Achievement & Degree & $\mathbf{1 6 . 8 6}^{*}$ & $\mathbf{0 . 0 0}$ & $\mathbf{0 . 9 4}$ & $\mathbf{3 . 6 8}$ & high \\
\hline Front wave & Degree & $23.94^{*}$ & $\mathbf{0 . 0 0}$ & $\mathbf{0 . 9 7}$ & 3.57 & high \\
\hline Arch Jump & Degree & $12.58^{*}$ & $\mathbf{0 . 0 0}$ & $\mathbf{0 . 8 9}$ & 3.38 & high \\
\hline Open Turn & Degree & $\mathbf{1 3 . 8 5}^{*}$ & $\mathbf{0 . 0 0}$ & $\mathbf{0 . 9 1}$ & $\mathbf{4 . 6 1}$ & high \\
\hline Balance Passe & Degree & $\mathbf{2 9 . 5 8 *}$ & $\mathbf{0 . 0 0}$ & $\mathbf{0 . 9 8}$ & $\mathbf{9 . 1 4}$ & high \\
\hline
\end{tabular}

Effect Size: less than 0.5: low

0.5:0.8 = mediate greater than $0.8=$ high

It's clear from the above table that the effect size ranged from (3.38 to 9.14) and those values are greater than 0.8 , indicating that the impact of the proposed recreational program has a high effect.

Table (3)

Statistical Signs of Confidence Scale and the Improvement Percentage, before and after the experiment $\quad n=20$

\begin{tabular}{|l|l|l|l|l|l|c|}
\hline Statistical Signs & Pretest & Posttest & Difference & T & Significance & Improvement \\
\hline
\end{tabular}




\begin{tabular}{|c|c|c|c|c|c|c|c|c|c|}
\hline & \multirow[b]{2}{*}{ Mean } & \multirow[b]{2}{*}{$\begin{array}{c}\text { Std. } \\
\text { Deviation } \\
\pm \\
\end{array}$} & \multirow[b]{2}{*}{ Mean } & \multirow[b]{2}{*}{$\begin{array}{c}\text { Std. } \\
\text { Deviation } \\
\pm\end{array}$} & \multicolumn{2}{|c|}{$\begin{array}{c}\text { between two } \\
\text { Means }\end{array}$} & \multirow[t]{2}{*}{ Value } & & \multirow[t]{2}{*}{ Percentage $\%$} \\
\hline & & & & & Mean & $\begin{array}{c}\text { Std. } \\
\text { Deviation } \\
\pm\end{array}$ & & & \\
\hline Self-Acceptance & 12.85 & 2.46 & 34.80 & 1.64 & 21.95 & 3.02 & 32.54* & 0.00 & 170.82 \\
\hline Others-Acceptance & 7.60 & 1.10 & 20.15 & 1.79 & 12.55 & 2.46 & 22.82* & 0.00 & 165.13 \\
\hline Social Activity & 8.40 & 1.60 & 20.10 & 2.25 & 11.70 & 2.47 & 21.16* & $\mathbf{0 . 0 0}$ & 139.29 \\
\hline Emotional Balance & 6.70 & 1.26 & 16.55 & 1.64 & 9.85 & 1.95 & 22.54* & 0.00 & 147.01 \\
\hline $\begin{array}{c}\text { Ability of Facing } \\
\text { Problems }\end{array}$ & 9.25 & 1.29 & 34.80 & 1.64 & 25.55 & 2.33 & 49.09* & 0.00 & 276.22 \\
\hline Axes Sum & 44.80 & 4.85 & 126.40 & 7.48 & 81.60 & 9.45 & 38.62* & 0.00 & 182.14 \\
\hline
\end{tabular}

Correlation is significant at the 0.05 level $=2.09$

It is clear from the above table that there are statistically significant differences in the level of (0.05), where the value of $(\mathrm{T})$ ranged between (21.16 to 38.62), which is greater than the tabulated value of $(\mathrm{T})$ at the level (0.05) with level of significance less than 0.05 , and the improvement ratios ranged between (139.29\% to 276.22\%) for the benefit of posttest in all the variables under consideration.

Table (4)

Significance of self-confidence according to Cohen Equations $\quad \mathbf{n = 2 0}$

\begin{tabular}{|c|c|c|c|c|c|c|}
\hline Statistical Signs & $\begin{array}{c}\text { Measurement } \\
\text { Unit }\end{array}$ & T Value & Significance & Eta Squared & $\begin{array}{c}\text { Effect } \\
\text { Size }\end{array}$ & Significance of Effect Size \\
\hline Self-Acceptance & Degree & $32.54^{*}$ & $\mathbf{0 . 0 0}$ & 0.98 & 10.04 & high \\
\hline $\begin{array}{c}\text { Others- } \\
\text { Acceptance }\end{array}$ & Degree & $22.82^{*}$ & $\mathbf{0 . 0 0}$ & $\mathbf{0 . 9 6}$ & $\mathbf{4 . 8 0}$ & high \\
\hline Social Activity & Degree & $21.16^{*}$ & $\mathbf{0 . 0 0}$ & $\mathbf{0 . 9 6}$ & $\mathbf{5 . 2 2}$ & high \\
\hline $\begin{array}{c}\text { Emotional } \\
\text { Balance }\end{array}$ & Degree & $22.54^{*}$ & $\mathbf{0 . 0 0}$ & $\mathbf{0 . 9 6}$ & $\mathbf{5 . 9 0}$ & high \\
\hline $\begin{array}{c}\text { Ability of Facing } \\
\text { Problems }\end{array}$ & Degree & $49.09 *$ & $\mathbf{0 . 0 0}$ & $\mathbf{0 . 9 9}$ & 11.81 & high \\
\hline Axes Sum & Degree & $38.62 *$ & $\mathbf{0 . 0 0}$ & $\mathbf{0 . 9 9}$ & $\mathbf{9 . 9 6}$ & High \\
\hline
\end{tabular}

Effect Size: less than 0.5=low $\quad 0.5: 0.8=$ mediate $\quad$ greater than 0.8= high

It's clear from the above table that the effect size ranged from (4.80 to 11.81) and those values are greater than 0.8 , indicating that the impact of the proposed recreational program has a high effect .

\section{Discussion of the Results:}

It is clear from Table (1) and Table (2) that the proposed program has led to improve cognitive achievement and technical performance of skills under study. Researchers believe that these results are because of the effect of the proposed recreational program using small games, which this program takes into account in the 
nature of the study's sample. Also, it takes into account raising the spirit of fun and performing exercises in the form of competitions. This led to high morale which had a positive impact on improving cognitive achievement and on the technical performance of the skills of rhythmic gymnastics.

In this regard Saleh Abbas (2000) refers that the principle of thrilling and excitement makes the students to not feel bored but increase motivation and desire to participate. (1: 191)

Magdy Aziz Ibrahim (2004) refers that the learners of different ages and in different stages of education have a desire of playing in general, because they find fun and recreation in sports activities. (7: 747)

Emad Hamdy shows (2001) that through small games, success is achieved in practicing activity which increases the enthusiasm and tendencies towards practicing and increasing the skill level. (5:3)

Abdul-Hamid Sharaf (2005) confirms that small gams are one of the method that can be used in kinetic activities of entertaining and these games are useful physical and mental, psychological and social methods. (3: 147)

Whitehead (1993) refers that the modern learning should be based on a feeling of happiness and fun. $(15: 150)$

Researchers believe that learning through recreational activities lead to master skills, and in this regard Tahany Abdul Salam (2001) says that one of the purposes of recreation activities is the educational purpose. (14:115)

It is clear from Table (3)and Table (4) that the proposed program has led to improve self-confidence of the students under study, because the proposed recreational program uses small games that collect between competition and the thrilling and this is in line with Taha Abdul Rahim where he refers (2006) that games and contests are very important for students in this age. (13:17)

In this regard Mohamed Azmi (1996) refers that the child loves competitions, but these competitions must be simple and light. (10:36)

Richard Kraus (2001) refers that participation in recreational programs increases self-confidence. (12: 124)

Mohamed Ahamahmy and Aida Mohamed Abdul Aziz (2001) refer that recreational activities contribute in achieving the humanitarian needs like self-expression and self-confidence and decreasing psychological stress and nervous tension associated with modern life, providing personal and family life full of happiness, stability, and confidence. (34: 9) 
Also researchers believe that self-confidence improvement came through the improvement in technical performance where Nemat Abdul Rahman, and Majda Rajab (2003) refer that the rhythmic gymnastics usefulness doesn't include the physical aspects only, but beyond to the moral, social and psychological aspects as they have educational value in through learning them accuracy, and working as a team. (11:30)

\section{Conclusions:}

Using the proposed program has led to improve :

1- The cognitive achievement in rhythmic gymnastics.

2- The technical performance of rhythmic gymnastics skills under study (Front wave - Arch Jump - Open Turn - Balance Passe) .

3- Self-confidence of students of sixth grade.

\section{References :}

1. Abbas Saleh: Teaching Styles of Physical Education, National Library for printing and publishing, University of Baghdad, 2000.

2. Abdel Fattah al-Khawaja: Psychology of Contemporary Psychotherapy, Dar El Mostakbal for publication and distribution, Jordan, 2001.

3. Abdul Hameed Sharaf: Motor and sports education of children without disabilities and with disabilities between theory and practice, Book publishing center, Cairo, 2005.

4. Aida Shaaban and Nagah Awad: Separation anxiety and its relationship with self-confidence for children with dead father in Gaza province, Educational Scientific Conference for psychology, Faculty of Education, University of Damascus, 2009.

5. Imad Hamdi: Impact of using some small games to learn some basic boxing motor skills, Master Thesis, Faculty of Physical Education for Men, University of Helwan, 2001.

6. Jaster Jembskaia, N. \& Titov. , Y: Rhythmic Gymnastics (Hoop- Ball - ChipsRibbon- Rope), Human Kinetics US A, 1999.

7. Magdy Aziz: learning strategies and styles, Anglo-Egyptian Library, Cairo, 2004.

8. Mohammed Abdullah: Introduction in small games, El Motahedon for Printing, Zagazig, 2005. 
9. Mohammed Ahamamy and Aida Abdul Aziz: Recreation between theory and practice, Book publishing center, Cairo, 2001.

10. Mohamed Azmi: Methods of developing and implementing physical education lesson in basic education between theory and practice, knowledge facility, Alexandria, 1996.

11. Nemat Abdul Rahman, Majda Rgab: Rhythmic gymnastics, Dar El Hakma, Cairo, 2003.

12. Richard Kraws: Recreation and leisure in society, Temple University James and Barlette ,2001.

13. Taha Abdul Rahim: Recreation, El Walaa for printing and publishing, Alexandria, 2006.

14. Tahany Abdul Salam: Recreation and recreational education, Dar El Arab for Printing, Alexandria, 2001.

15. Whitehead: Why not happiness change and conflict in early education, New York, vintage Book 1993. 